\title{
ANALISIS SISTEM KERJA MANAJEMEN KONSTRUKSI DALAM PROYEK PEMBANGUNAN GEDUNG POLTEKKES 5 LANTAI DI TEMBALANG
}

\author{
Ahmad Falasifadin ${ }^{1}$, Dadang Suryo Wibowo ${ }^{2}$, Hari Setijo Pudjihardjo ${ }^{3}$ \\ ${ }^{1}$ Fakultas Teknik Jurusan Teknik Sipil Universitas Semarang \\ ${ }^{2}$ Fakultas Teknik Jurusan Teknik Sipil Universitas Semarang \\ ${ }^{3}$ Fakultas Teknik Jurusan Teknik Sipil Universitas Semarang
}

\begin{abstract}
ABSTRAK: Manajemen konstruksi bisa dikatakan suatu pekerjaan yang dilakukan dengan tujuan untuk mengatur, mengorganisir dan mengkoordinir semua pekerjaan yang dilaksanakan dan terlibat dalam pembangunan sebuah proyek konstruksi. Sedangkan Manajemen konstruksi pada proyek adalah proses penerapan fungsi-fungsi manajemen pada suatu proyek dengan sumber daya yang ada secara efektif dan efisien agar tercapai tujuan proyek secara optimal.

Pada saat ini di Kota Semarang, Jawa Tengah telah dibangun gedung Poltekkes 5 lantai di Tembalang yaitu gedung pascasarjana yang dibangun oleh Kemenkes dengan menggunakan jasa Manajemen Konstruksi. Manajemen Konstruksi yang dipilih dari PT. Bina Karya dengan kontraktor pelaksananya dari PT. Jaya Arnikon dan perencananya dipercayakan oleh PT. Yodya Karya. Dengan adanya jasa Manajemen Konstruksi di Gedung ini, kami memilih untuk mengetahui sistem kerja Manajemen Konstruksi yang diterapkan dalam proyek konstruksi sehingga dapat berjalan dengan baik dan sesuai dengan yang dijadwalkan.

Proyek ini dilaksanakan dalam 202 hari kalender yang selesai pada tanggal 31 Desember 2016 kemarin, kemudian dilanjutkan dengan masa pemeliharaan gedung selama 6 bulan berikutnya. dengan melakukan metode kuesioner untuk tugas akhir ini penulis memilih beberapa responden yang terlibat dalam proses pekerjaan pembangunan di lingkungan proyek tersebut maupun dari luar proyek yang memiliki kesamaan dalam pembangunan gedung bertingkat. Kuesioner yang digunakan sebanyak 30 orang responden yang berpartisipasi menjawab dan mengisi kuesioner.
\end{abstract}

Kata kunci: manajemen konstruksi, proyek konstruksi, analisis

ABSTRACT: Construction management can be said of a work performed for the purpose of arranging, organizing and coordinating all the work carried out and involved in the development of a construction project. Meanwhile, construction on the project management is the process of implementing management functions on a project with existing resources effectively and efficiently in order to achieve project objectives optimally. At this time in Semarang, Central Java has built 5-storey building in Tembalang polytechnic is a graduate of buildings constructed by the Ministry of Health to use the services of Construction Management. Construction Management selected from PT. Bina Karya with the executing contractor of PT. Jaya Arnikon and planners entrusted by PT. Yodya work. With the Construction Management services in this building, we choose to know the working system applied in Construction Management in construction projects so it can run well and according to schedule. The project was implemented within 202 calendar days which was completed on December 31, 2016 yesterday, then proceed with building maintenance period during the next 6 months. to perform the method questionnaire for this thesis the author chose some of the respondents involved in the process of development work in the project environment or from outside the project that has similarities in the construction of multi-storey building. The questionnaire used as many as 30 respondents who participated answered and fill out a questionnaire.

Keywords: construction management, construction projects, analysis

\section{Pendahuluan}

Manajemen konstruksi bisa dikatakan suatu pekerjaan yang dilakukan dengan tujuan untuk mengatur, mengorganisir dan mengkoordinir semua pekerjaan yang dilaksanakan dan terlibat dalam pembangunan sebuah proyek konstruksi. Pekerjaan konstruksi dapat dikatakan baik apabila semua pelaksanaan pembangunan dapat berjalan sesuai rencana. Sistem pengelolaan pembangunan dalam pekerjaan konstruksi dapat dikatakan mempunyai pengaruh seperti yang diharapkan dengan melakukan penataan akan semua proses kegiatan pekerjaan konstruksi yang akan dilaksanakan sehingga mendapatkan hasil pekerjaan yang baik. 
Manajemen konstruksi mempunyai arti dimana proses kerja antara pemilik dengan orang manajemen konstruksi dengan memberikan tugas untuk mengkoordinir dan mengomunikasikan seluruh kegiatan saat proses pelaksanan proyek yang diantaranya seperti dari studi desain konstruksi, perencanaan, persiapan kontrak, mutu bahan, harga bahan, jadwal rencana dan lainnya. Dengan kata lain manajemen konstruksi mencakup semua proses yang ada dari penyelenggaran prakonstruksi, proses pelaksanaan sampai dengan akhir pekerjaan dengan asumsi sampai tidak ada masalah diakhir pekerjaan konstruksi.

Pada saat ini di Kota Semarang, Jawa Tengah telah dibangun gedung Poltekkes 5 lantai di Tembalang yaitu gedung pascasarjana yang dibangun oleh Kemenkes dengan menggunakan jasa Manajemen Konstruksi. Manajemen Konstruksi yang dipilih dari PT. Bina Karya dengan kontraktor pelaksananya dari PT. Jaya Arnikon dan perencananya dipercayakan oleh PT. Yodya Karya. Dengan adanya jasa Manajemen Konstruksi di Gedung ini, kami memilih untuk mengetahui sistem kerja Manajemen Konstruksi yang diterapkan dalam proyek konstruksi sehingga dapat berjalan dengan baik dan sesuai dengan dijadwalkan. Proyek ini dilaksanakan dalam 202 hari kalender yang selesai pada tanggal 31 Desember 2016 kemarin, kemudian dilanjutkan dengan masa pemeliharaan gedung selama 6 bulan berikutnya.

\section{Metode Penelitian}

Metodologi penelitian menurut Sugiyono (2010:2) berupa metode penelitian yang pada dasarnya merupakan cara ilmiah untuk mendapatkan data dengan tujuan dan kegunaan tertentu. Sedangkan menurut I Made Wirartha (2006:68) adalah suatu cabang ilmu pengetahuan yang membicarakan atau mempersoalkan cara-cara melaksanakan penelitian (yaitu meliputi kegiatan-kegiatan mencari, mencatat, merumuskan, menganalisis sampai menyusun laporannya) berdasarkan fakta-fakta atau gejala-gejala secara ilmiah. Sehingga dengan definisi dari metodologi penelitian tersebut bisa diartikan sebagai teknik pendekatan untuk melakukannya dengan tujuan melakukan peninjauan objek demi mendapatkan data dari sebuah penelitian agar menjadi jelas.

Sumber data terbagi menjadi dua yaitu data primer dan data sekunder. Data primer adalah data yang diperoleh peneliti secara langsung (dari tangan pertama), sementara data sekunder adalah data yang diperoleh peneliti dari sumber yang sudah ada. Pengambilan sampel penelitian ini menggunakan random sampling yaitu setiap individu dalam populasi memiliki kesempatan yang sama untuk dipilih menjadi anggota sample. Pada umumnya penelitian atau studi tentang masalah hubungan faktor-faktor yang mempengaruhi dalam penerapan manajemen kontruksi pada pembangunan gedung berdasarkan presepsi kontraktor atau para penyedia jasa kontruksi pada proyek pembangunan gedung yamg khususnya berada di kota Semarang.

Selain itu data penelitian ini merupakan data kuantitatif, yaitu suatu data yang dikumpulkan dan diolah untuk mencari atau mendapatkan seberapa besar faktor-faktor yang mempengaruhi dalam penerapan manajemen kontruksi pada pembangunan gedung di kota Semarang. Pada penelitian ini target responden adalah responden yang bergerak dalam bidang usaha jasa kontruksi pembangunan gedung di sekitar kota semarang. Jumlah responden akan diberi kuesioner kurang lebih 30 responden. Pengumpulan data akan dibagikan kepada pihak-pihak yang terkait dalam pembangunan Gedung Poltekkes 5 lantai di Tembalang ini dan juga dari beberapa perusahaan yang bergerak dibidang jasa konstruksi yang akan ikut juga dalam kuesioner untuk bersedia berpendapat dalam pembangunan proyek ini.

\section{Hasil dan Pembahasan}

Berdasarkan hasil analisa penerapan manajemen konstruksi pada proyek pembangunan gedung Poltekkes 5 lantai di Tembalang dapat diberikan kesimpulan bahwa: 
a. Urutan 3 (tiga) teratas dari faktor-faktor yang berpengaruh dalam penerapan sistem kerja manajemen konstruksi menurut hasil analisa yaitu:

1. "Skedul waktu sesuai dengan proses di lapangan", memiliki urutan yang ke 1 (satu). Hal tersebut menunjukkan bahwa target pekerjaan dapat terpenuhi dan bisa selesai dengan tepat waktu serta dapat dijadikan kontrol dari kemajuan pengerjaan proyek.

2. "Tidak kesesuaian mutu material yang digunakan", memiliki urutan yang ke 2 (dua). Mutu material yang baik akan menghasilkan pekerjaan yang berkualitas dan dapat dipertanggung jawabkan secara nyata melalui hasil tes / uji coba, misal : tes kuat tekan beton.

3. "Birokrasi yang panjang saat menyelesaikan masalah yang terjadi di proyek", memiliki urutan yang ke 3 (tiga). Penanganan masalah yang lama bisa menimbulkan banyak masalah yang lain juga terutama pekerjaan yang tidak akan dimulai sebelum solusi ditemukan sehingga menyebabkan pekerjaan lain terbengkalai.

b. Urutan 3 (tiga) terbawah dari faktor-faktor yang berpengaruh dalam penerapan sistem kerja manajemen konstruksi menurut hasil analisa yaitu:

1. "Kejelasan dalam penentuan spesifikasi material pada RAB", memiliki urutan yang ke 3 (tiga) dari bawah. Hal ini menjadi salah satu yang berpengaruh untuk memudahkan dalam pelaksanaan proyek konstruksi. Spesifikasi material yang jelas memudahkan dalam mencari material dan sesuai dengan keinginan pemilik.

2. "Hasil pekerjaan saat pelaksanaan yang sesuai dengan rencana awal", memiliki urutan yang ke 2 (dua) dari bawah. Fungsi dari perencanaan yaitu mengetahui hasil dari bangunan sebelum dilaksanakan. Jadi hasil pekerjaan yang dilaksanakan tetap mengacu dari perencanaan sehingga saat sudah jadi berharap tidak jauh beda dari perencanaan dari suatu bangunan konstruksi yang sudah direncanakan sejak awal.

3. "Kemajuan teknologi dalam penggunaan metode pelaksanaan", memiliki urutan yang ke 1 (satu) dari bawah. Teknologi membuat pekerjaan semakin mudah dan cepat.

c. Urutan 3 (tiga) teratas dari tindakan-tindakan yang berpengaruh dalam penerapan sistem kerja manajemen konstruksi menurut hasil analisa yaitu:

1. "Mengantisipasi dan memantau kondisi lapangan dengan cermat", memiliki urutan yang ke 1 (satu). Kondisi lapangan yang baik menjadikan langkah - langkah yang diambil dari proses pekerjaan menjadi lebih mudah.

2. "Mengejar proses pengerjaan di lapangan dengan cepat dan tepat dalam menyelesaikan masalah keterlambatan proses pengerjaan", memiliki urutan yang ke 2 (dua). Terlambat dalam proses pengerjaan menimbulkan banyak kerugian bagi banyak pihak yang terlibat dalam suatu pembangunan konstruksi dari segi biaya dan waktu juga. Oleh karena itu, sangat dibutuhkan proses pengerjaan yang cepat agar selesai dengan tepat waktu.

3. "Menerapkan tenaga ahli yang sesuai dengan pekerjaanya dalam pembagian rangkaian pekerjaan", memiliki urutan yang ke 3 (tiga). Orang yang benar ditempat yang tepat seperti yang dikatakan oleh pepatah sehingga menjadikan pekerjaan konstruksi tertangani dengan baik dan tepat.

d. Urutan 3 (tiga) terbawah dari tindakan-tindakan yang berpengaruh dalam penerapan sistem kerja manajemen konstruksi menurut hasil analisa yaitu:

1. "Mengecek dan mengontrol harga material sebelum diajukan ke pemilik", memiliki urutan yang ke 1 (satu) dari bawah. Harga menjadi dasar dalam mengajukan sebuah anggaran maka setiap perhitungan harus disampaikan kepada pemilik yang terkait dengan anggaran yang digunakan.

2. "Pengalihan menggunakan metode lain dalam pekerjaan khusus di proyek sehingga dapat dialihkan dengan menggunakan alat yang lain", memiliki urutan yang ke 2 (dua) dari bawah. Mencari alat yang susah dicari karena mungkin ditempat yang terpencil maupun alat khusus dapat menunda pekerjaan sehingga 
waktu akan terbuang. Dengan menggunakan metode lain agar pekerjaan dapat dilakukan dengan cepat dan tepat sehingga dapat selesai dengan tepat waktu.

3. "Menggunakan teknologi yang sesuai dengan kondisi proyek", memiliki urutan yang ke 3 (tiga) dari bawah. Teknologi yang sesuai berarti sesuai dengan pekerjaan yang dilakukan dengan dasar kegunaan, biaya dan waktu sehingga efisiensi waktu dapat teratasi dengan bantuan teknologi yang memudahkan dalam melakukan pekerjaan konstruksi.

e. Sedangkan faktor yang paling berpengaruh dalam penerapan sistem kerja manajemen konstruksi yang dikelompokkan menurut fungsi manajemen, yaitu :

1. Perencanaan (planning), faktor yang paling berpengaruh adalah "pekerjaan yang terjadwal pada proyek", karena hal tersebut menunjukkan bahwa target pekerjaan dapat terpenuhi dan bisa selesai dengan tepat waktu serta dapat dijadikan kontrol dari kemajuan pengerjaan proyek.

2. Pengorganisasian (organizing), faktor yang paling berpengaruh adalah "birokrasi yang panjang saat menyelesaikan masalah yang terjadi di proyek", karena hal tersebut menyebabkan penanganan masalah yang lama dan bisa menimbulkan banyak masalah yang lain juga terutama pekerjaan yang tidak akan dimulai sebelum solusi ditemukan sehingga menyebabkan pekerjaan lain terbengkalai.

3. Pelaksanaan (actuating), faktor yang paling berpengaruh adalah "kedatangan material/peralatan yang dibutuhkan tepat waktu", karena jika tidak ada material maka pekerjaan tersebut tidak akan terlaksana. Dengan terlambatnya kedatangan material maka pekerjaan pun akan terhambat serta dapat menghambat pekerjaan lain juga jika saling berhubungan antara pekerjaan yang satu dengan yang lainnya.

4. Pengendalian (controling), faktor yang paling berpengaruh adalah "skedul waktu sesuai dengan proses di lapangan", karena hal tersebut menunjukkan bahwa target pekerjaan dapat terpenuhi dan bisa selesai dengan tepat waktu serta dapat dijadikan kontrol dari kemajuan pengerjaan proyek.

Dari hasil analisis mengenai faktor-faktor yang berpengaruh dalam penerapan Sistem Kerja Manajemen Konstruksi yang sudah di kelompokan diantara ke 4 kelompok fungsi tersebut, bahwa fungsi manajemen Organisasi (Organizing) memiliki nilai faktor paling berpengaruh dalam penerapan Sistem Kerja Manajemen Konstruksi ini, karena faktor dari fungsi organisasi berpengaruh dalam menata pekerjaan agar berjalan dengan lancar, kemudian dilanjutkan dengan Pengendalian (Controlling), Perencanaan (Planning) dan Pelaksanaan (Actuating).

f. Berikut tindakan yang paling berpengaruh dalam penerapan sistem kerja manajemen konstruksi yang dikelompokkan menurut fungsi manajemen, yaitu :

1. Perencanaan (planning), tindakan yang paling berpengaruh adalah "mendata pekerjaan baik dari tambahan pekerjaan sehingga lebih mudah dalam pengalihan ke pekerjaan lain", karena dengan tertata dan tersusun rapi rencana pekerjaan akan lebih mudah untuk mengetahui pekerjaan yang belum dilaksanakan serta dapat mengetahui mengalihkan pekerjaan yang satu ke pekerjaan lain karena ada masalah yang belum terselesaikan. Jadi tidak menyia-nyiakan waktu saat ada pekerjaan lain yang terhambat.

2. Pengorganisasian (organizing), tindakan yang paling berpengaruh adalah "menerapkan tenaga ahli yang sesuai dengan pekerjaanya dalam pembagian rangkaian pekerjaan", karena seperti pepatah mengatakan orang yang benar ditempat yang tepat sehingga menjadikan pekerjaan konstruksi tertangani dengan baik dan tepat.

3. Pelaksanaan (actuating), tindakan yang paling berpengaruh adalah "pengalihan pekerjaan yang lain yang dapat dikerjakan saat kondisi cuaca sedang buruk", karena kondisi cuaca yang memang tak bisa diprediksi tetapi dengan pengalihan pekerjaan lain yang tidak berpengaruh dengan kondisi cuaca dapat terus dilaksanakan tanpa harus menunda waktu lagi.

4. Pengendalian (controling), tindakan yang paling berpengaruh adalah "mengantisipasi dan memantau kondisi lapangan dengan cermat", karena kondisi 
lapangan yang baik menjadikan langkah-langkah yang diambil dari proses pekerjaan menjadi lebih mudah.

Dari hasil analisis mengenai tindakan-tindakan yang berpengaruh dalam penerapan Sistem Kerja Manajemen Konstruksi yang sudah di kelompokan diantara ke 4 kelompok fungsi tersebut, bahwa fungsi manajemen Pengendalian (Controling) memiliki nilai paling berpengaruh dalam tindakan penerapan Sistem Kerja Manajemen Konstruksi ini, karena faktor dari fungsi pengendalian berpengaruh dalam mengendalikan mutu, biaya dan waktu, kemudian dilanjutkan dengan Organisasi (Organizing), Perencanaan (Planning) dan Pelaksanaan (Actuating).

\section{SARAN}

Dikarenakan penelitian analisa penerapan manajemen konstruksi pada proyek pembangunan gedung Poltekkes 5 lantai di Tembalang ini tidak melalui pengamatan secara langsung ke lapangan sehingga agar dapat lebih memahami mengenai penerapan sistem manajemen konstruksi perlu adanya adanya pengamatan langsung di lapangan dengan jangka waktu cukup lama pada proyek yang di tinjau. Dengan melakukan pengamatan langsung di lapangan diharapkan mendapatkan gambaran yang lebih jelas mengenai penerapan sistem manajemen konstruksi.

\section{DAFTAR PUSTAKA}

Augusty Tae Ferdinand, 2006. Metode Penelitian Manajemen, Edisi II. Badan Penerbit : Universitas Diponegoro. Semarang.

Badan Standarisasi Nasional, 2001. Sistem Manajemen Mutu Persyaratan, SNI ISO 9001 : 2008.

Budi Santoso, 2003. Manajemen Proyek. Guna Widya. Jakarta.

Clough dan Sears, 1991. Construction Project Management. John Willey and Sons Incoporation. Canada.

Depdikbud, 1996. Kamus Besar Bahasa Indonesia. Balai Pustaka. Jakarta.

Dispohusodo, 1996. Manajemen dan Konstruksi. Kanisius. Yogyakarta.

George R. Terry, 2000.Prinsip-Prinsip Manajemen (edisi bahasa Indonesia). PT. Bumi Aksara. Bandung.

Harold Kerzner, 2001. Project Management : A System to Planning, Scheduling and Controlling, 7th Edition, John Wiley \& Sons.

I Made Wirartha, 2006. Metodologi Penelitian Sosial Ekonomi, hal. 68. C.V. Andi Offset. Yogyakarta.

Iman Soeharto, 1999. Manajemen Proyek (Dari Konseptual sampai Operasional), Jilid 1, Hal. 28. Erlangga. Jakarta.

Iman Soeharto, 1995. Manajemen Proyek (Dari Konseptual sampai Operasional). Erlangga. Jakarta.

Kathy Schwalbe, 2006. Information Technologi Project Management, Edisi ke-4. Couerse Technology. Boston Massachusetts.

Render dan Heizer, 2001. Prinsip-Prinsip Manajemen Operasi, di-Indonesiakan oleh Arianto. Salemba Empat. Jakarta.

Roscoe, J.T., 1975. Fundamental Research Statistic for The Behavior Sciencess. (2nd, ed), Holt, Rinehart and Winston. New York.

Shenhar, Levy dan Dvir, 1997."Mapping the Dimension of Project Success", Project Management Journal, vol. 28, no. 2, pp. 5-13.

Silalahi, Ulber, 2006. Metode Penelitian Sosial Bandung, hal. 311 - 313. Unpar Press. Bandung.

Sugiyono, 2004. Metode Penelitian Bisnis. Alfabeta. Bandung.

Sugiyono, 2007. Metode Penelitian pendidikan pendekatan kuantitatif, kualitatif dan R\&D, hal. 163. Alfabeta. Bandung.

Sugiyono, 2010. Statistika untuk Peneltian, hal. 2. Alfabeta. Bandung

Wibowo, 2009. Manajemen Kinerja, edisi-2. PT. Raja Grafindo Persada. Jakarta.

Wulfram I. Ervianto, 2005. Manajemen Proyek Konstruksi. Andi Offset. Yogyakarta. 